\title{
Taxonomy of effective strategies to reduce unnecessary caesareans: a systematic review
}

Leila Eslambolchi, ${ }^{1}$ Ali Mohammad Mosadeghrad, ${ }^{2}$ Sara Taheri ${ }^{1}$ and Mahnaz Afshari ${ }^{3}$

${ }^{1}$ Health Management and Economics Department, School of Public Health, Tehran University of Medical Sciences, Tehran, Islamic Republic of Iran. ${ }^{2}$ Health Economics and Management Department, Health Information Management Research Centre, Tehran University of Medical Sciences, Tehran, Islamic Republic of Iran (Correspondence to: Ali Mohammad Mosadeghrad: mosdeghrad@yahoo.com). 3Department of Health Service Management, School of Health Management and Information Sciences, Iran University of Medical Sciences, Tehran, Islamic Republic of Iran.

\begin{abstract}
Background: The increasing trend in unnecessary caesarean sections has caused maternal and neonatal health concerns worldwide. Various medical and non-medical interventions have been designed and implemented to reduce caesarian section overuse. However, their efficacy is questionable.

Aims: This study aimed to identify and classify effective interventions to reduce unnecessary caesarian sections.

Methods: We searched EMBASE, MEDLINE, Web of Knowledge and Scopus databases for articles, using appropriate search strategies, up to 2 June 2020. Overall, 7951 identified articles were screened and assessed using a valid quality assessment checklist. Finally, 109 eligible studies were included in this review. Thematic content analysis was used to identify and classify the effective interventions.

Results: Overall, 188 effective caesarian section reduction measures were identified. They were categorized into 45 actions, 16 intervention groups and 6 WHO building blocks, including "governance and leadership", "financing", "health workforce", "medical products and technologies", "information" and "service delivery". Using qualified and competent staff, intra-partum services, and oversight were the most commonly applied interventions to reduce unnecessary caesarian sections.

Conclusions: A taxonomy of effective strategies to reduce unnecessary caesarian sections was developed in this study. A holistic approach is crucial to addressing the new epidemic of unnecessary caesarian section. Multiple interventions based on the underlying causes of caesarian section overuse should be designed and implemented at local and global levels.

Keywords: pregnancy, caesarean section, caesarean reduction interventions, unnecessary procedures

Citation: Eslambolchi L; Mosadeghrad AM; Taheri S; Afshari M. Taxonomy of effective strategies to reduce unnecessary caesarean: a systematic review. East Mediterr Health J. 2021;27(8):826-849. https://doi.org/10.26719/emhj.21.046

Received: 13/11/19, accepted: 16/11/20

Copyright (C) World Health Organization (WHO) 2021. Open Access. Some rights reserved. This work is available under the CC BY-NC-SA 3.0 IGO license (https://creativecommons.org/licenses/by-nc-sa/3.o/igo).
\end{abstract}

\section{Introduction}

Caesarean section (CS), the surgical mode of birth, was introduced to save the lives of mothers and infants, and having access to this procedure is a vital part of comprehensive emergency obstetric care (1). According to the World Health Organization (WHO) statement of 1985, a CS rate of $10-15 \%$ at the population level is accepted and there is no justification for having more CSs in any region in the world (2). The WHO readdressed this issue due to the controversy on the optimum CS rate in 2015 and emphasized that a rate greater than $10 \%$ had no benefit for reducing maternal and neonatal mortality. Considering the potential risks, it was strongly recommended to restrict performing the procedure to medically indicated reasons and applying appropriate interventions to prevent unnecessary CSs.

Moreover, more research has been called for to investigate the immediate and future effects of CS on health (3). However, the global figures show an increasing trend worldwide. The average CS rate rose from $6.7 \%$ in 1990 to $21 \%$ in 2015 , with a $3.7 \%$ average annual increase from 2000 to 2015 (4). The WHO experts estimated that a third of CS procedures, about 6 million worldwide each year, were unnecessary in 2010 (5).

A variety of reasons, from health system-related issues to health care user's concerns, affect the rising trend of CS (6). Fear of labour pain or assumed damage to the body and baby or even the temptation of choosing the baby's date of birth are some reasons for a women to request CS $(7,8)$. In addition, private practice, defensive medicine, financial incentives and convenience induce physicians to perform more CSs (9). Generating revenues for hospitals, financial reimbursements and quality of maternity services are some of the reasons rooted in the health system (9).

There is robust evidence that costly unnecessary CSs (5) are associated with increased maternal and neonatal mortality and morbidity. More surgical complications, hospital readmissions and problems in subsequent pregnancies such as uterine rupture, abnormal placentation, ectopic pregnancy, stillbirth, and preterm birth have been reported after a CS $(9,10)$. Surgically born 
babies are more prone to neonatal death and neonatal intensive care unit (NICU) admissions due to serious complications. They might also suffer from short-term health risks like altered immune development, allergy, atopy, asthma, and reduced intestinal gut microbiome diversity and long-term risks such as type 1 diabetes, asthma, overweight and even cognitive and educational problems (10).

Target 3.1 of the United Nations Sustainable Development Goals asks states to reduce their maternal mortality ratio by 2030 (11). Obviously, preventing unnecessary caesareans would protect women and babies from the adverse effects of this surgical procedure. Various strategies have been introduced and applied worldwide to combat the epidemic of unnecessary CS. There have been some systematic reviews on solo interventions such as continuous support during childbirth (12) or controlling mothers' fear of labour (13). Valuable studies on antenatal and intrapartum interventions (14) and nonclinical interventions (15) have been published in recent years too, which have provided robust evidence for designing caesarean reduction strategies. However, considering the complex and complicated nature of CS overuse, a holistic approach is needed to control the increasing trend worldwide.

The 6 building blocks of the health system, governance and leadership, financing, health workforce, medical products and technologies, information and service delivery (16), should be considered in any comprehensive health related plan. Hence, this study aimed to identify effective interventions to reduce unnecessary caesareans and classify them using the WHO 6 building blocks framework.

\section{Methods}

This was a systematic review of studies. It followed the Preferred Reporting Items for Systematic Reviews and Meta-Analyses (PRISMA) guideline (17). Studies were searched systematically, identified, screened and reviewed. We systematically searched 4 electronic databases, EMBASE, PubMed (MEDLINE), Web of Knowledge and Scopus, and 2 search engines (Google scholar and Google) to identify relevant articles published up to 2 June 2020. The PICO (population, intervention, comparison, and outcome) search strategy tool was used to develop an effective strategy. English language original quantitative studies in which the participants were pregnant women, with any intervention aiming to decrease caesarean or increase vaginal births and with statistically significant results were included in this study. The search strategy involved 3 components (caesarean, reduction and strategies). In addition, medical subject headings $(\mathrm{MeSH})$ terms were used. Table 1 shows the search strategy in the PubMed database.

The initial search identified 7951 articles. After deleting duplicates, initial assessment of 7682 titles and abstracts was done by screening them against the inclusion and exclusion criteria by 2 researchers (all by LE and $20 \%$ by ST). Disagreements were resolved through discussion or by consulting a third reviewer (AMM). Then, the quality of articles was assessed using a quality assessment checklist (18). This tool evaluates the quality of articles in 5 areas (literature review and identification of research gaps, research questions and design, population and sampling, data collection and capture, and analysis and results). All articles were scored on a 4-point Likert scale: o (not present/not reported), 1 (present but low quality), 2 (present and midrange quality) and 3 (present and high quality). Each article was rated independently by 2 researchers and disagreements were resolved through discussion or by consulting a third reviewer if necessary. Those articles with a core of $\geq 10$ out of 15 were included in this study. Ultimately 109 studies were eligible (Figure 1).

A data extraction form covering the authors' names, publication year, country, research method, sample size, interventions, results and article quality scores was used in this study. Thematic content analysis was applied for data analysis. First the interventions were read and data were coded according to their content. Then, similar codes were grouped into themes called actions; similar actions were grouped as intervention groups. Finally, similar interventions were grouped and classified under the WHO 6 building blocks.

\section{Results}

\section{Overview}

One hundred and nine (109) original quantitative studies employing observational $(75.2 \%)$, experimental $(22.9 \%)$ and quasi-experimental $(1.8 \%)$ methods were included in this review. They were published from 1988 to 2020 , mostly $2010-2020(70 \%)$. The majority of studies were carried out in the United States of America (USA) (29\%), followed by the Islamic Republic of Iran (11.2\%) and Canada $(8.4 \%)$. Considering the WHO regions, these studies were conducted in the Americas (41.3\%), Europe (23.9\%), Western Pacific (17.4\%), Eastern Mediterranean (11.9\%),

\footnotetext{
Table 1 Search strategy terms in PubMed

(((()Intervention? OR program OR project OR "evidence based" OR policy OR education adj2 (program OR meeting? OR session? OR strateg OR workshop? OR visit?)))) AND (“Cesarean Section"[Mesh] OR "Parturition"[Mesh] OR "Delivery, Obstetric"[mesh] OR "Cesarean Sections"[tiab] OR "Delivery, Abdominal"[tiab] OR “Abdominal Deliveries"[tiab] OR “Deliveries, Abdominal"[tiab] OR "Caesarean Section"[tiab] OR "Caesarean Sections" [tiab] OR "Abdominal Delivery"[tiab] OR “C-Section (OB)"[tiab] OR “C Section (OB)"[tiab] OR "C-Sections (OB)"[tiab] OR "Postcesarean Section"[tiab] OR “Delivery, Obstetric"[tiab] OR “Deliveries, Obstetric"[tiab] OR “Obstetric Deliveries”[tiab] OR “Obstetric Delivery"[tiab] OR "Parturition"[ tiab] OR "Parturitions"[tiab] OR "Birth"[tiab] OR "Births"[tiab] OR "Childbirth"[tiab] OR "Childbirths"[tiab] OR VBAC OR "Vaginal Birth After Cesarean"))) AND ((Elective OR voluntary OR chosen OR willing OR Elective Cesarean?))
} 


\section{Figure 1 Flow chart outlining search strategy and selection of articles on caesarean section (CS) up to 2 June 2020}

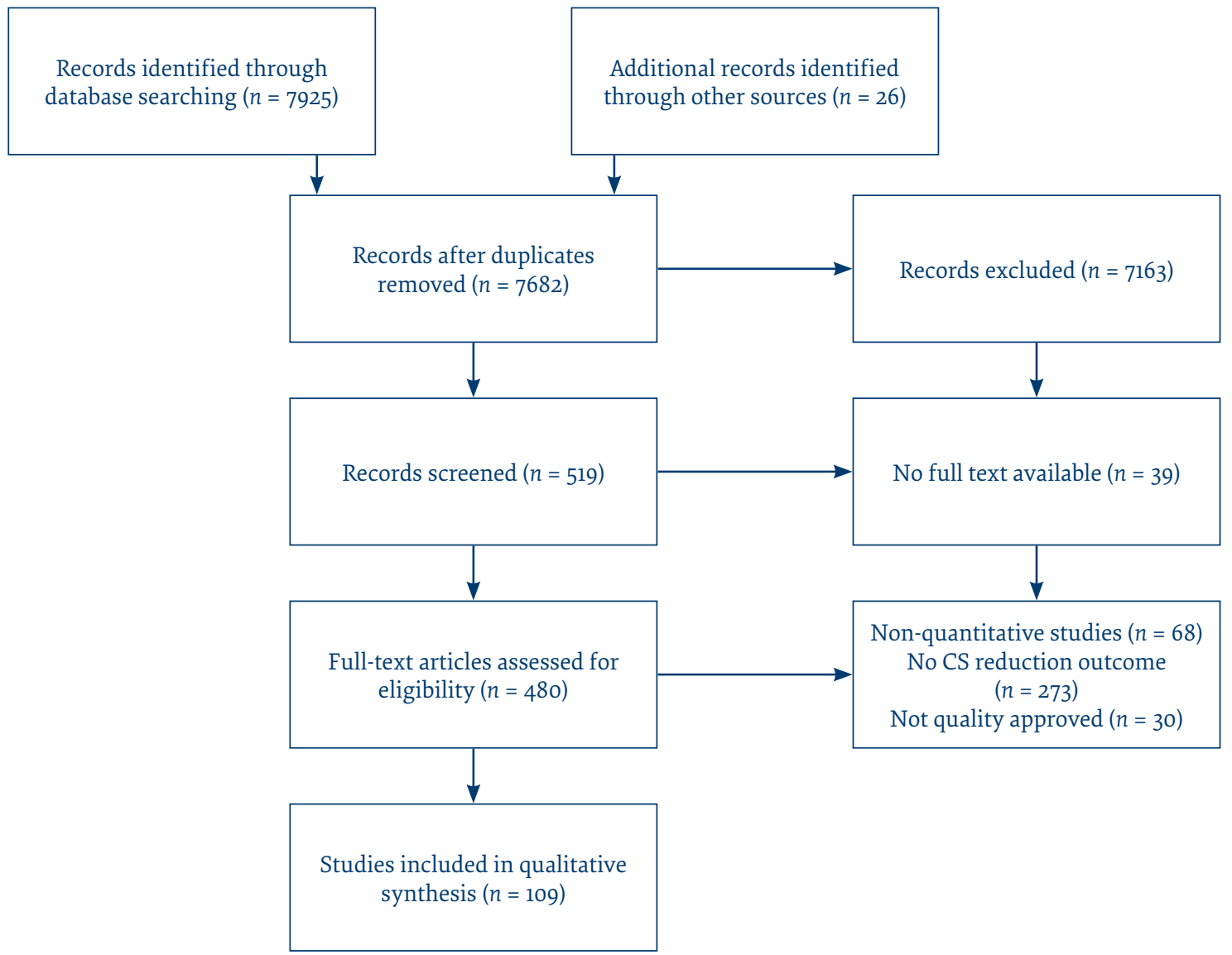

Africa (3.7\%) and South-East Asia (1.8\%) regions. A descriptive summary of the studies is presented in Table 2.

Overall, 188 codes (measures) were identified and classified into 45 effective actions to reduce unnecessary
CSs. These actions were grouped into 16 intervention groups and finally classified into the WHO 6 building blocks (Table 3). The most commonly used interventions were: using qualified and competent staff (17.4\%),

Table 2 Descriptive summary of the studies reviewed

\begin{tabular}{|c|c|}
\hline Element & Details \\
\hline Publication year & $\begin{array}{l}\text { Range: } 1988-2020 \\
\text { Mode: } 2017 \text { (16 studies) }\end{array}$ \\
\hline Sample size & $\begin{array}{l}\text { Range: } 67-10171742 \text { deliveries } \\
\text { Median: } 5201\end{array}$ \\
\hline \multicolumn{2}{|l|}{ Method (No.) } \\
\hline Observational (82) & Case-control (5), cross sectional (7), prospective cohort (10), retrospective cohort (60) \\
\hline Experimental (25): & Cluster randomized controlled trial (4), non-randomized controlled trial (1), randomized controlled trial (20) \\
\hline Quasi-experimental (2) & Natural experiment design (1), before-after (1) \\
\hline \multicolumn{2}{|l|}{ Country (No.) } \\
\hline Single country studies (107) & $\begin{array}{l}\text { USA (31), Islamic Republic of Iran (12), Canada (9), China (9), Australia (5), Sweden (5), Taiwan (3), UK (3), } \\
\text { Brazil (2), India (2), Ireland (2), Israel(2), Italy (2), Spain (2), Turkey (2), Burkina Faso (1), Lithuania(1), Chile } \\
\text { (1), Denmark (1), Ecuador (1), Egypt (1), Finland (1), Jordan (1), Lithuania (1), New Zealand (1), Pakistan (1), } \\
\text { Portugal (1), Singapore (1), The Netherlands (1), Ukraine (1), Zimbabwe (1) }\end{array}$ \\
\hline Studies in > 1 country $(2)$ & UK and the Netherlands (1), Latin America (1) \\
\hline WHO Region (No.) & Americas (45), Europe (26), Western Pacific (19), Eastern Mediterranean (13), Africa (4), South-East Asia (2) \\
\hline No. of interventions applied in each study & $\begin{array}{l}\text { 1: } 60 \text { studies } \\
\geq 2: 49 \text { studies }\end{array}$ \\
\hline Quality assessment score (15 scores) & $\begin{array}{l}\text { Range: } 10-15 \\
\text { Median: } 13\end{array}$ \\
\hline
\end{tabular}




\begin{tabular}{|c|c|c|}
\hline Building block & Intervention & Action \\
\hline \multirow[t]{6}{*}{ Governance \& leadership } & Legislation & Laws, regulations \\
\hline & Policy-making & CS rate goal setting, policies \\
\hline & Planning & Care models, quality improvement plans, patient safety plans \\
\hline & Promotion & $\begin{array}{l}\text { Use of media for promoting normal birth, nongovernmental organization } \\
\text { collaboration }\end{array}$ \\
\hline & Oversight & Audit, peer review, second opinion, evaluating and ranking obstetrics centres \\
\hline & Leadership & Leading by obstetricians, leading by midwives \\
\hline \multirow[t]{2}{*}{ Financing } & Institution reimbursement & Fixed per patient reimbursement, pay-for-performance \\
\hline & Provider reimbursement & Fixed per patient reimbursement, pay-for-performance \\
\hline \multirow[t]{2}{*}{ Health workforce } & Qualified \& competent staff & $\begin{array}{l}\text { Optimizing health workforce, staff education and training, supervising } \\
\text { obstetrics residents, changing staff attitude towards normal delivery }\end{array}$ \\
\hline & Team work & Group health providers, collaborative care \\
\hline \multirow[t]{2}{*}{ Medical products \& technologies } & Medicine & Using induction drugs, using medicines for regional anaesthesia \\
\hline & Equipment \& technology & $\begin{array}{l}\text { Using equipment and techniques to facilitate birth, using fetal wellbeing } \\
\text { assessment technologies }\end{array}$ \\
\hline \multirow[t]{2}{*}{ Information } & Data gathering \& analysis & Electronic medical records, measuring indicators, classification of CS \\
\hline & Information dissemination & Giving feedback to obstetricians, external dissemination of information \\
\hline \multirow[t]{2}{*}{ Service delivery } & Prenatal services & $\begin{array}{l}\text { Dietary counselling, exercise plan in prenatal period, control the woman's fear, } \\
\text { prenatal education, prenatal special clinics }\end{array}$ \\
\hline & Intra-partum services & $\begin{array}{l}\text { Protocol (evidence)-based practice, continuous care, physical and emotional } \\
\text { support, physiologic birth, pain control services, vaginal birth after caesarean } \\
\text { delivery }\end{array}$ \\
\hline
\end{tabular}

intra-partum services (14.1\%) and oversight (13.7\%). The interventions reported in the articles we reviewed for this study are summarized in Table 4 and some examples are described below.

\section{Governance and leadership}

Legislation, policy-making, planning, promotion, oversight and leadership interventions were classified as subgroups of the governance and leadership building block. Laws and regulations enforced the reduction of unnecessary CSs in some countries. In Texas (USA), a law was passed to eliminate Medicaid payment for early elective deliveries in 2011; this was followed by Georgia, Michigan, New Mexico, New York and South Carolina in 2013 (19). In China, rules and regulations were also applied to control caesarean delivery on maternal request, and obliged providers to encourage mothers to choose vaginal delivery (20).

Policy-making, including setting goals and defining policies, was also employed. In North Carolina, a target of $28.5 \%$ reduction in CS $(27.9 \%$ to $21.7 \%)$ for nulliparous women with a term, singleton pregnancy and vertex presentation was set in 3 hospitals in 2015. The hospitals achieved a 19.7\% CS rate, beyond the established goal (21). National and provincial policies were established in some countries such as the Normal Delivery Promotion Plan in the Islamic Republic of Iran (22) and the Healthy Texas Babies initiative in the USA (19).

Planning included designing different models of care, quality improvement or patient safety programmes. The community-based model for continuity of care (23) and the team-based shared-care model (24) were successful in reducing caesareans in Australia and Canada. The Lean Six Sigma technique was adopted in Tiazhou, a tertiary hospital in Zhejiang province, China in 2014. Using the Lean Six Sigma methodology (define, measure, analyse, improve and control) reduced the CS rate from $41.8 \%$ to $32 \%$ over a period of 10 months (25). The Patient Safety Bundle" is a patient safety programme implemented in 3 hospitals in North Carolina, USA. It comprised 4 stages: readiness, recognition and prevention, response, and reporting and systems learning, and resulted in a reduction in the CS rate from $27.9 \%$ to $19.7 \%$ (21).

Promotional interventions through collaboration with media and nongovernmental organizations were also influential in reducing the CS rate. Public campaigns to raise awareness about caesarean like the "Go the Full 40" campaign in the USA were launched (26). Social media and nongovernmental organization collaboration, creating a special WeChat group, holding professional forums on www.dxy.cn (the largest Chinese biomedical blog), and providing a monthly webinar called "Modern L\&D Virtual Lecture Hall" via YY Voice, a Chinese webbased education application, were used to promote a CS reduction plan in China (27).

Oversight was one of the most commonly used interventions, employed in almost every plan to reduce caesarean overuse. It was implemented by conducting medical audits and peer reviews and asking for second opinions $(28,29)$. The performance of birth facilities was also evaluated, ranked and reported to the public in some countries like China and the USA (21,30). 


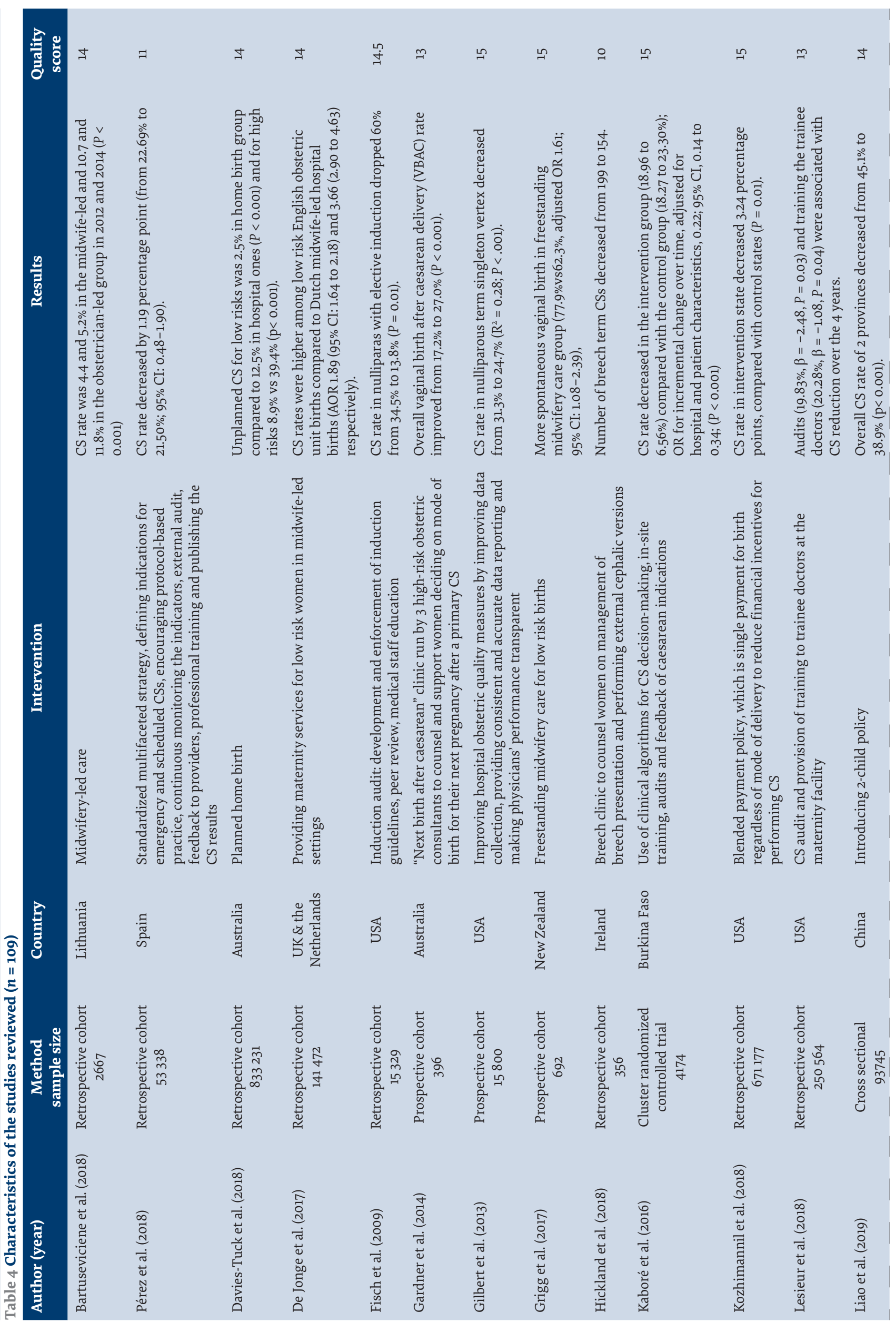




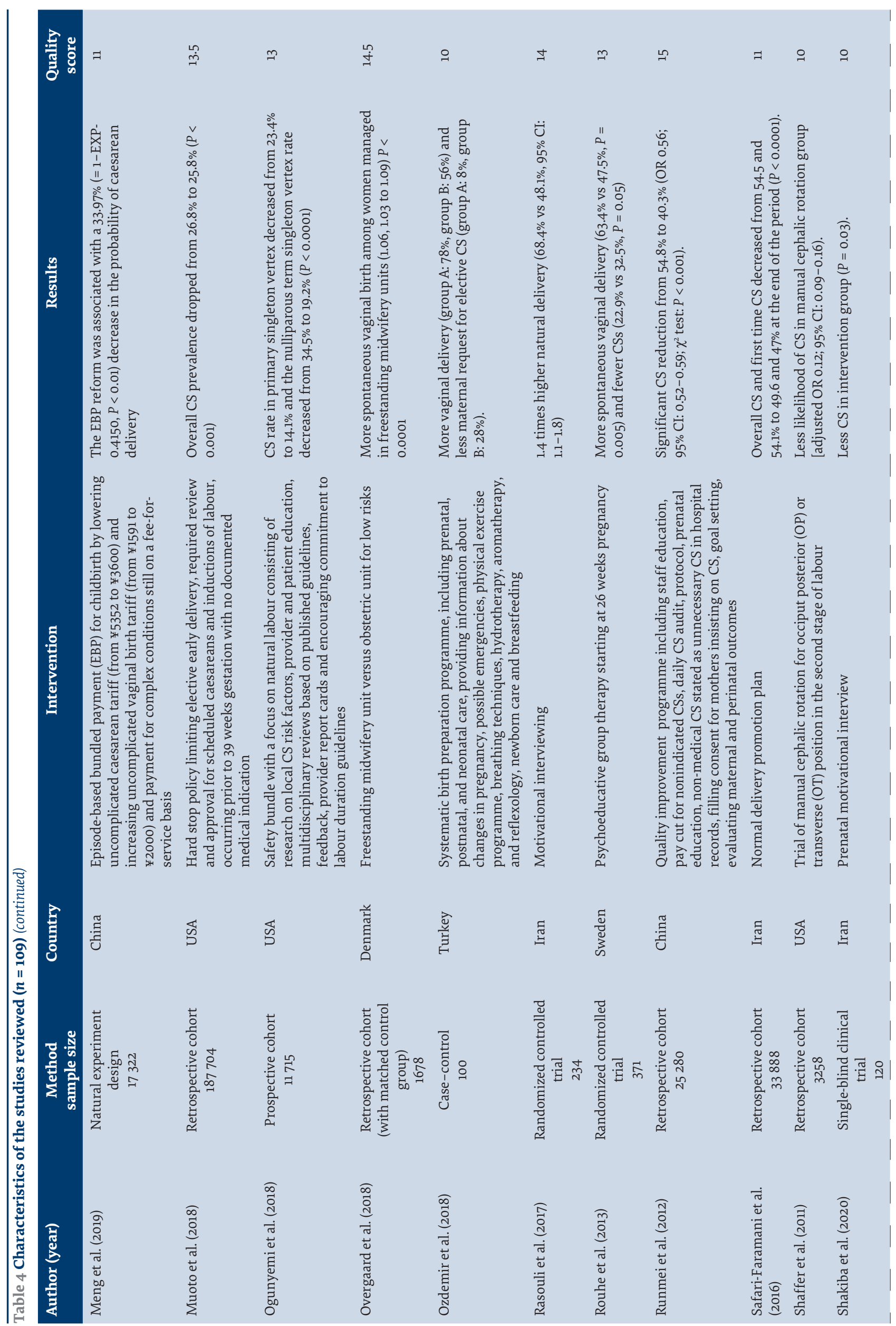




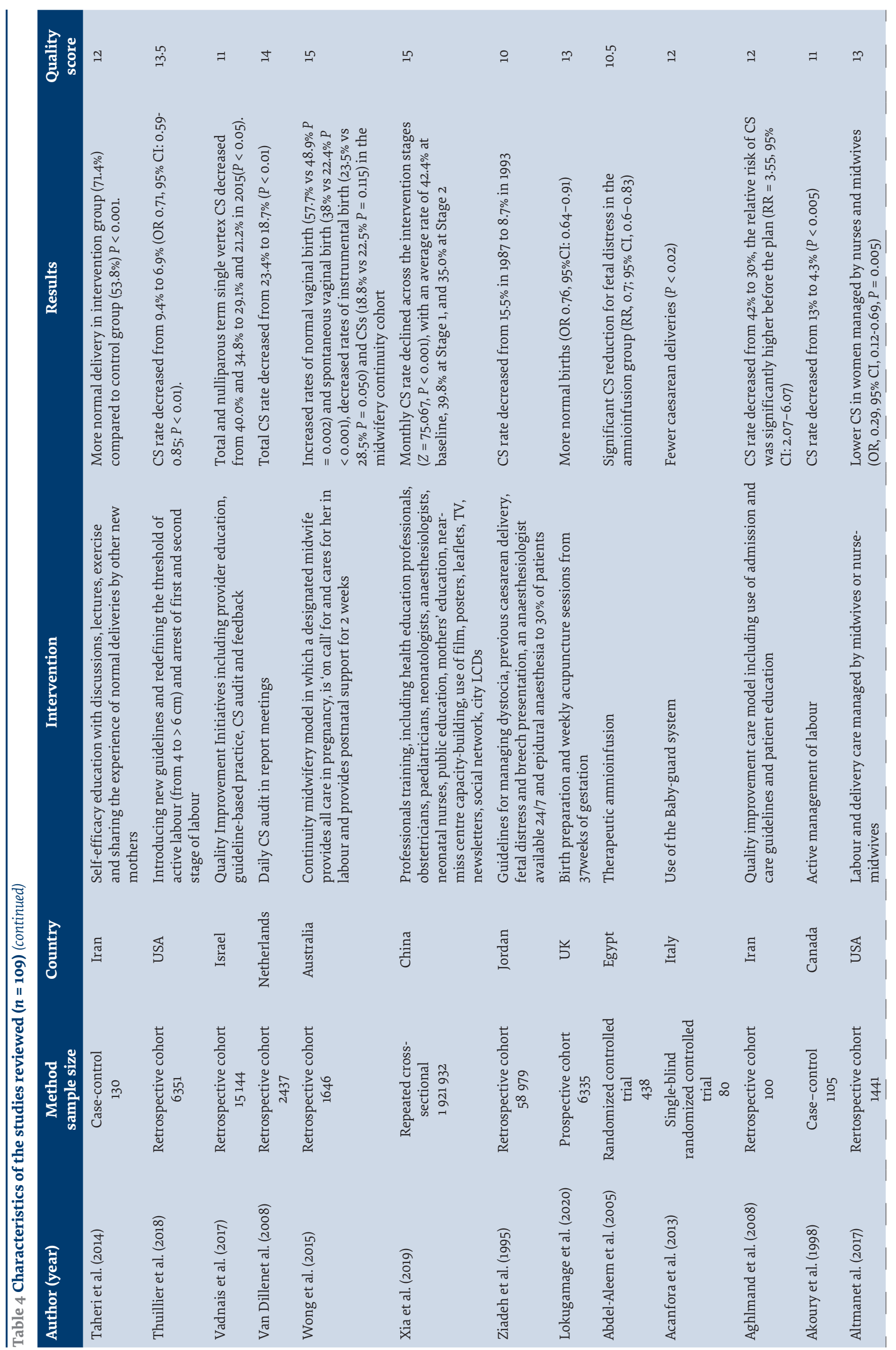




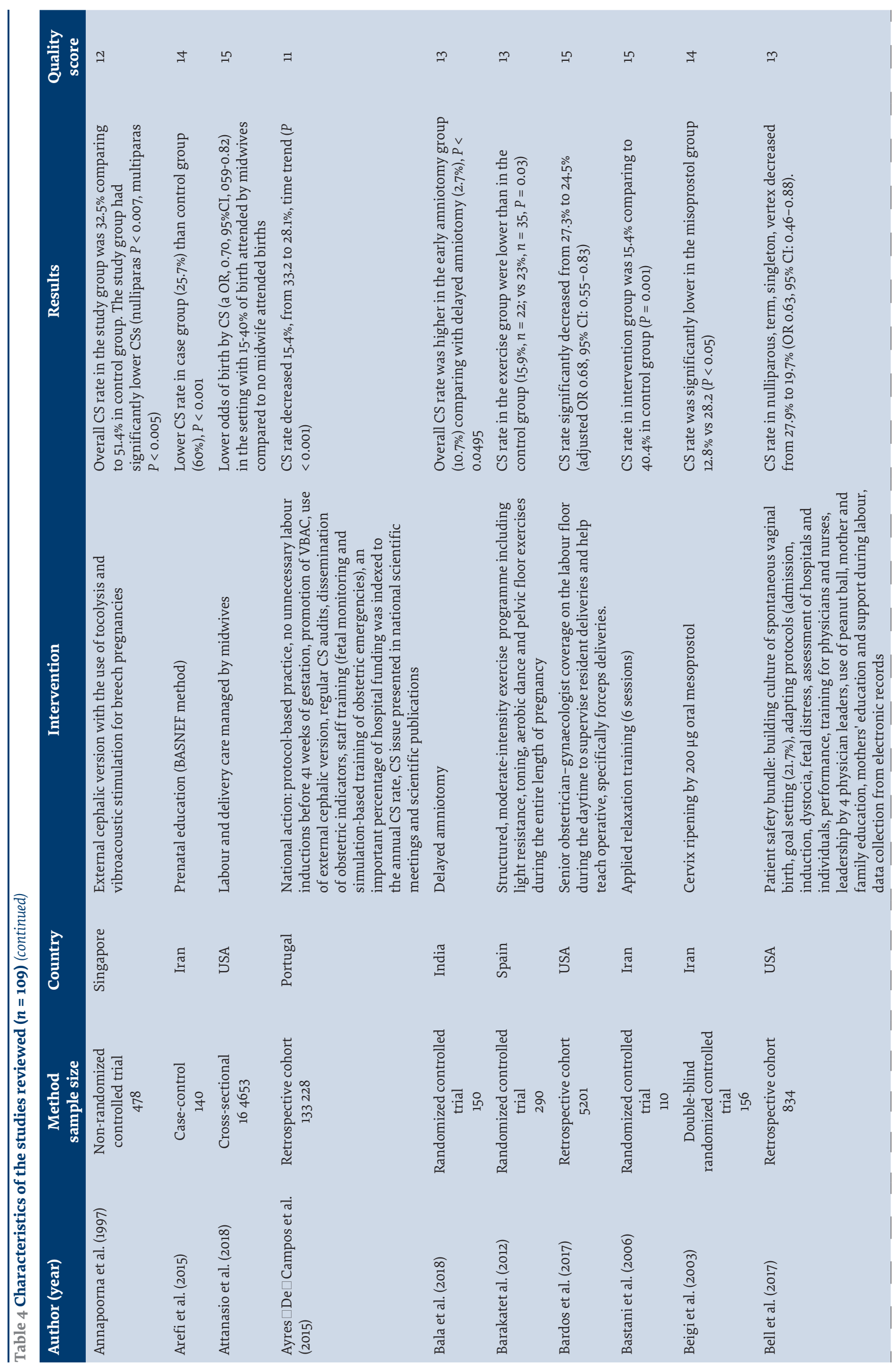




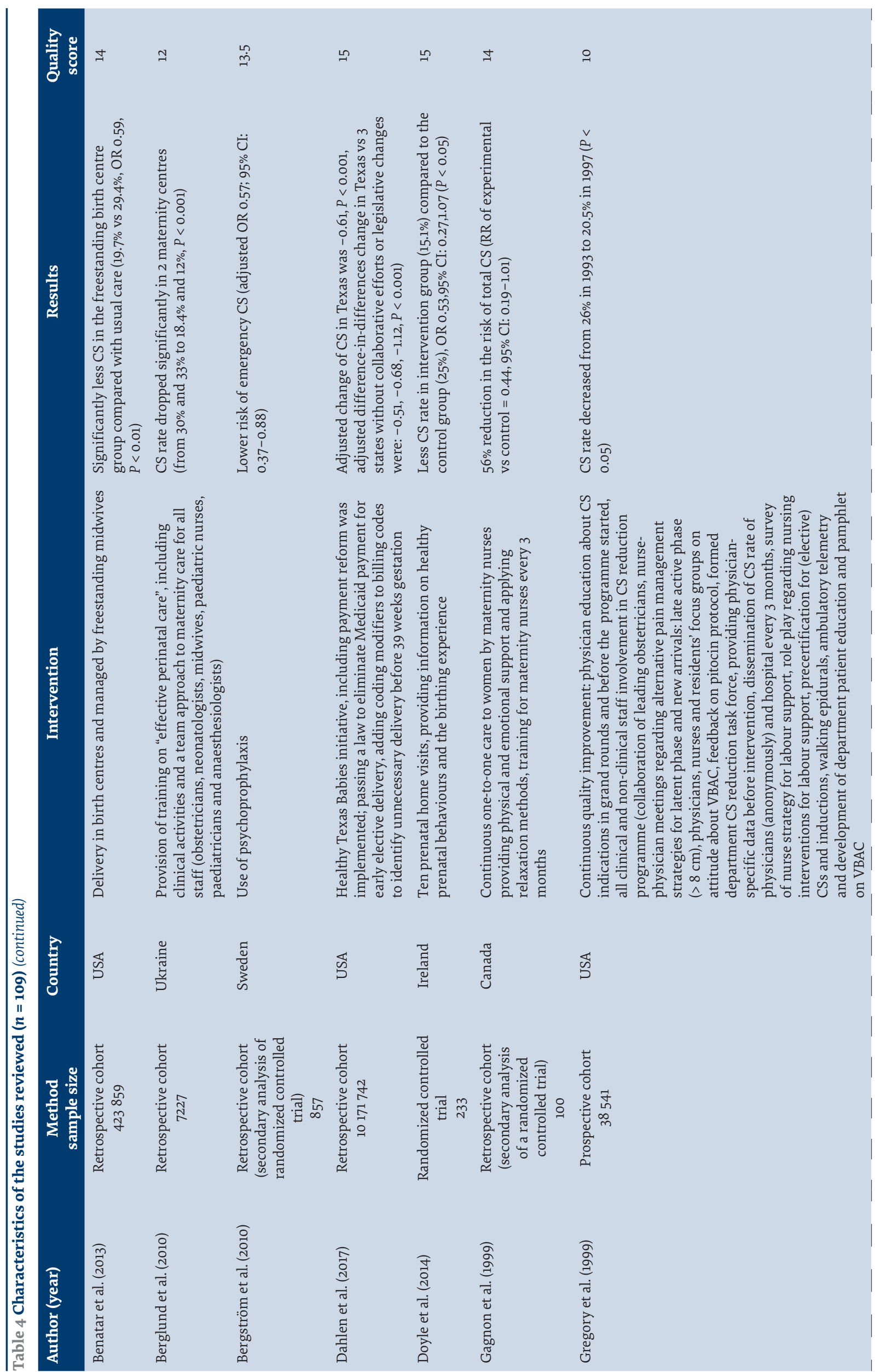




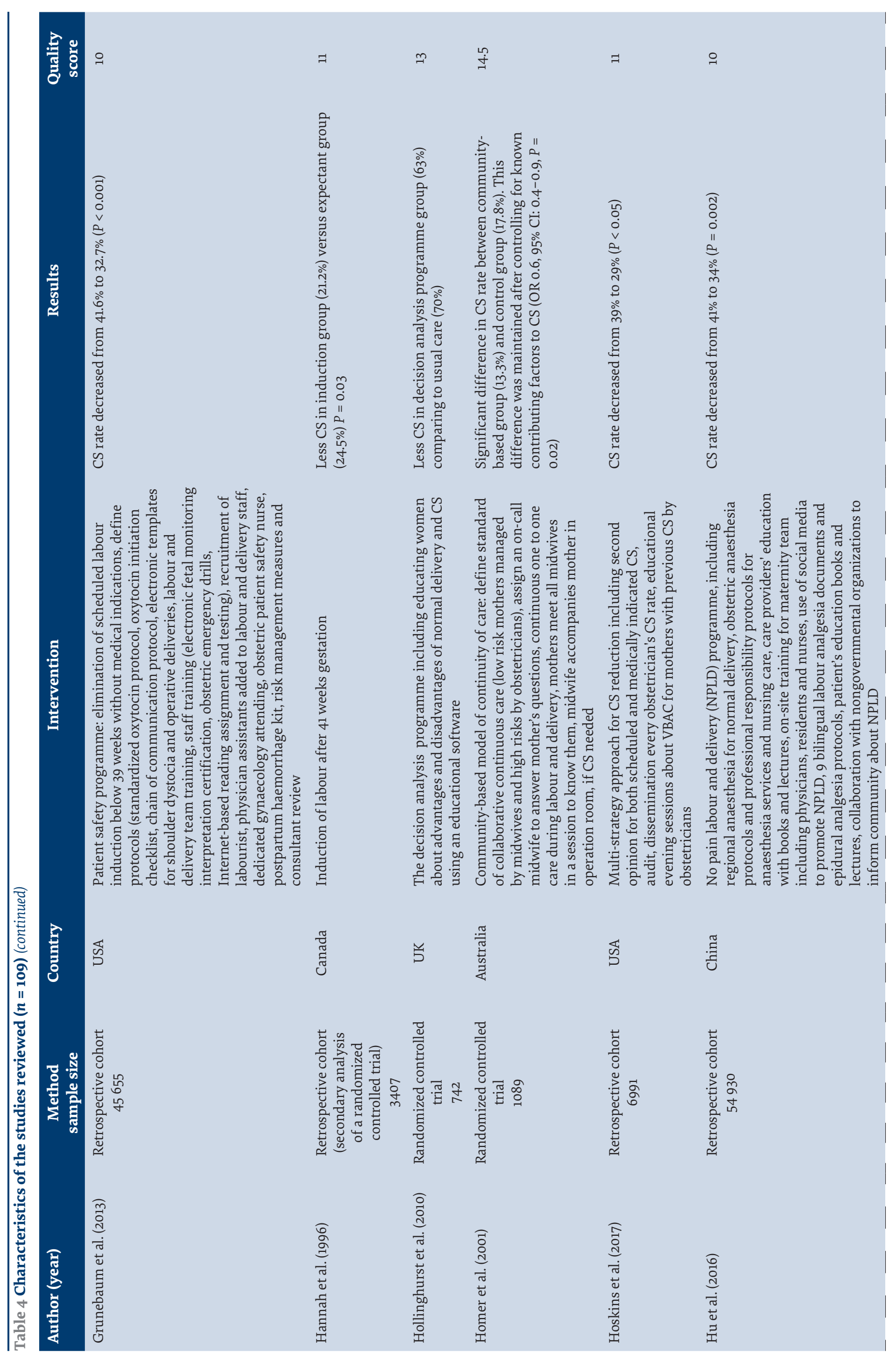




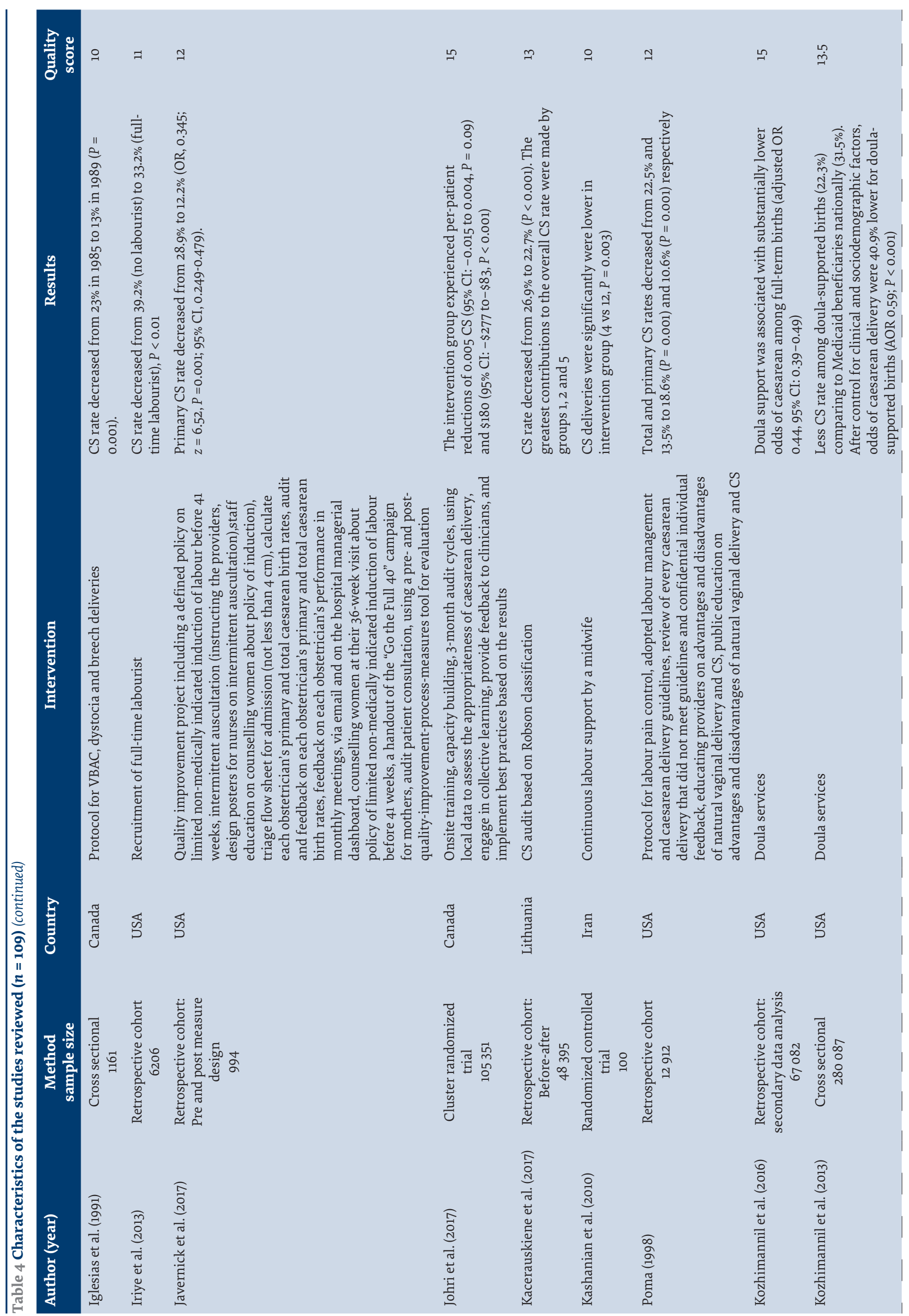




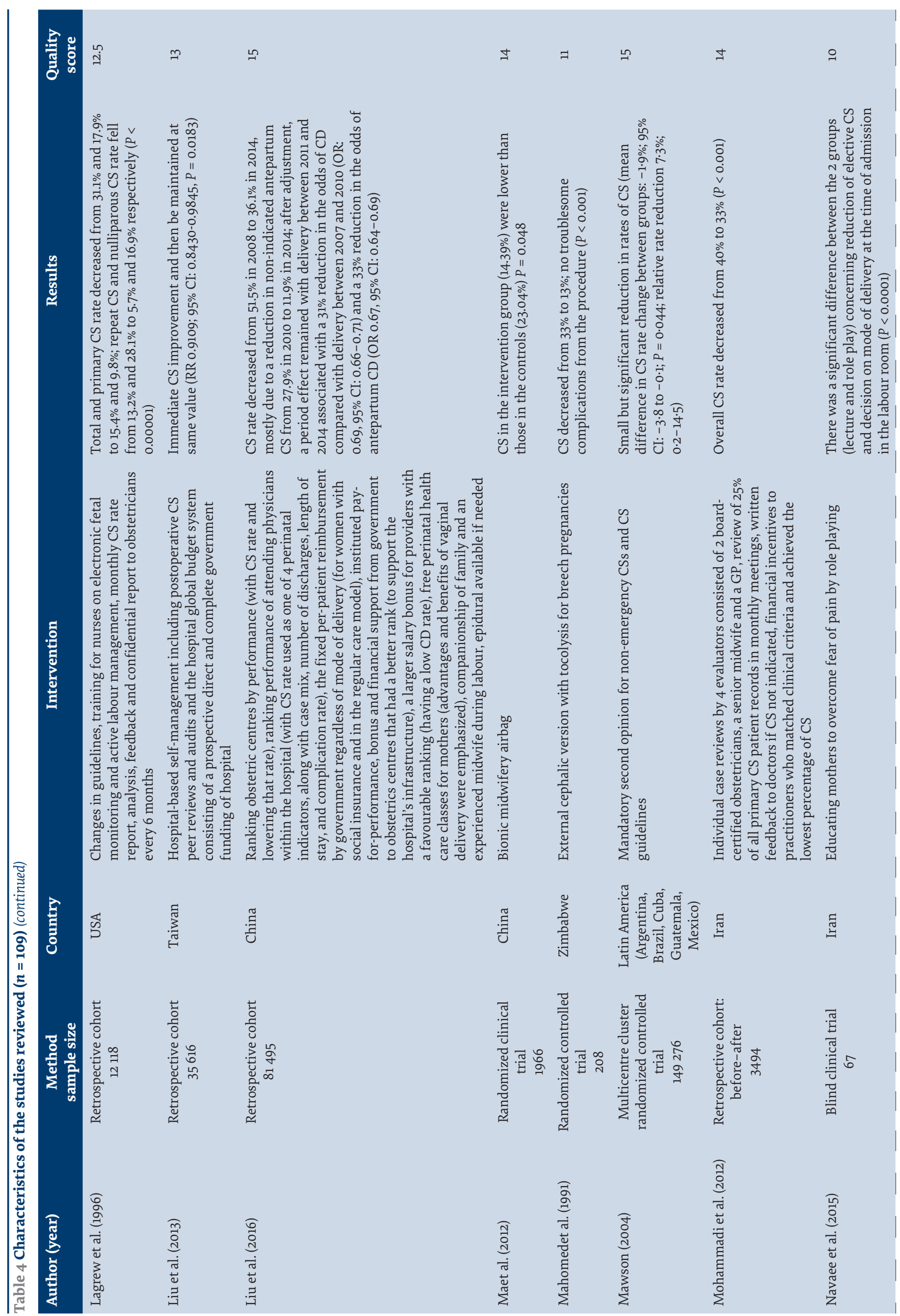




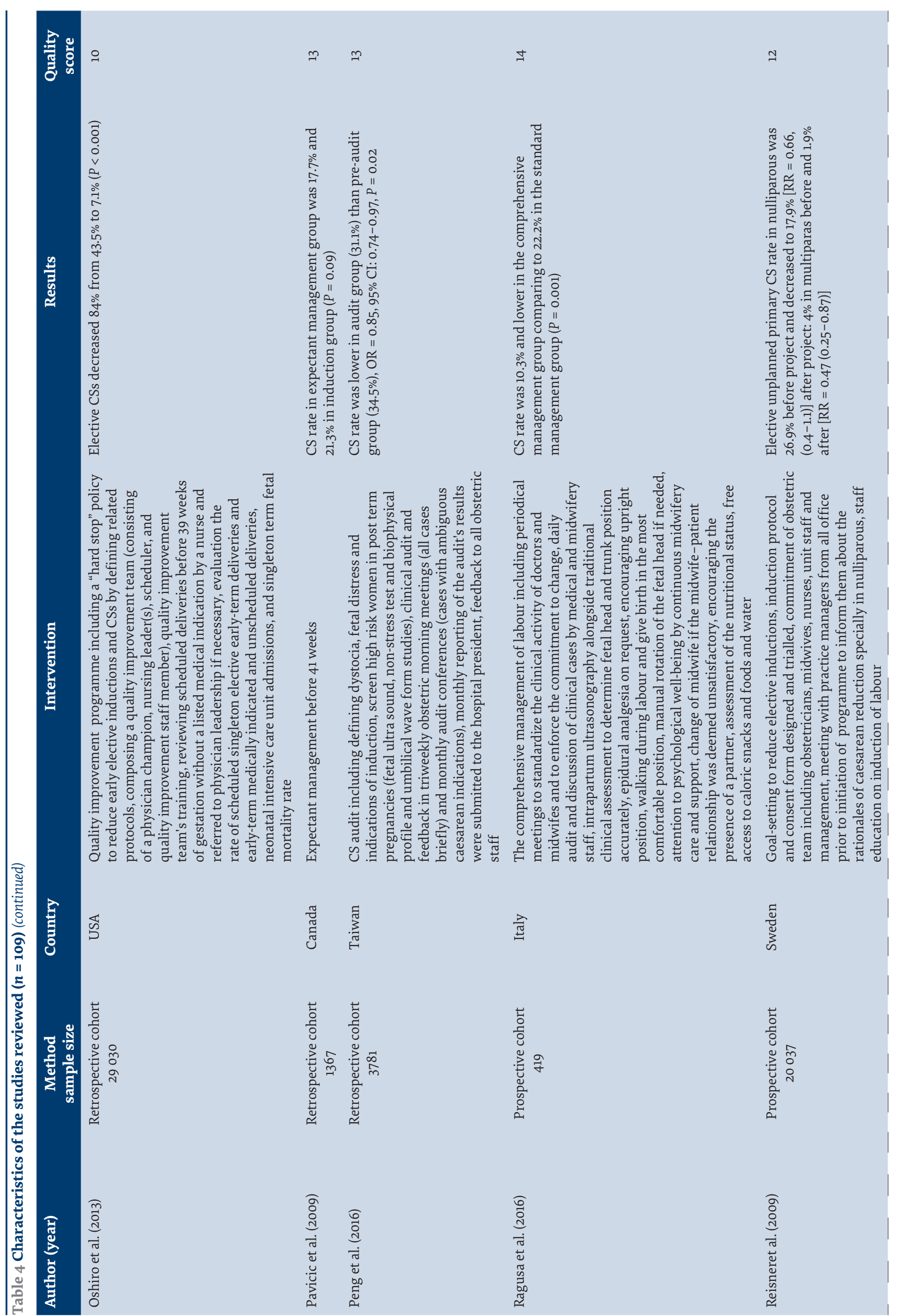




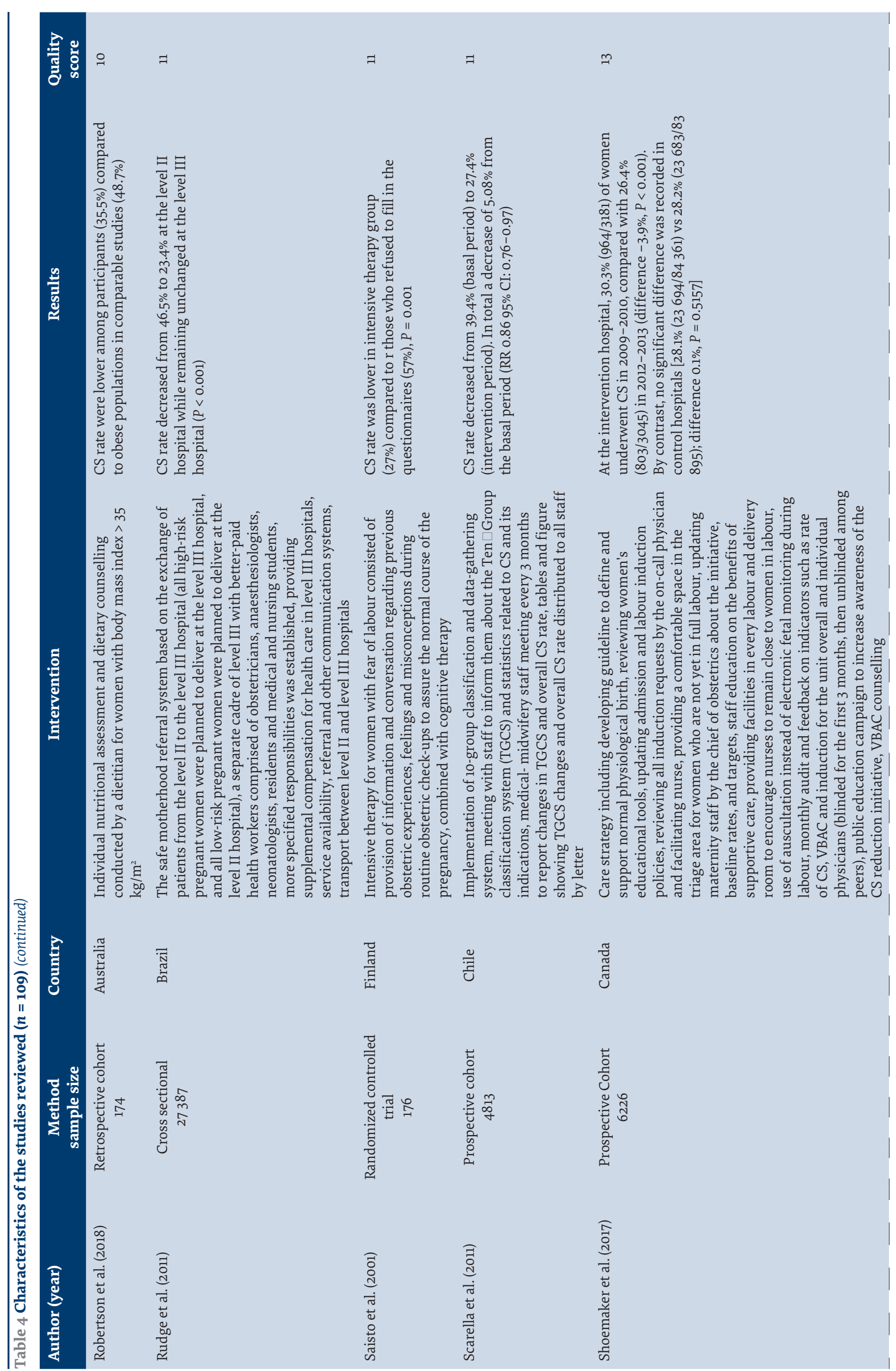




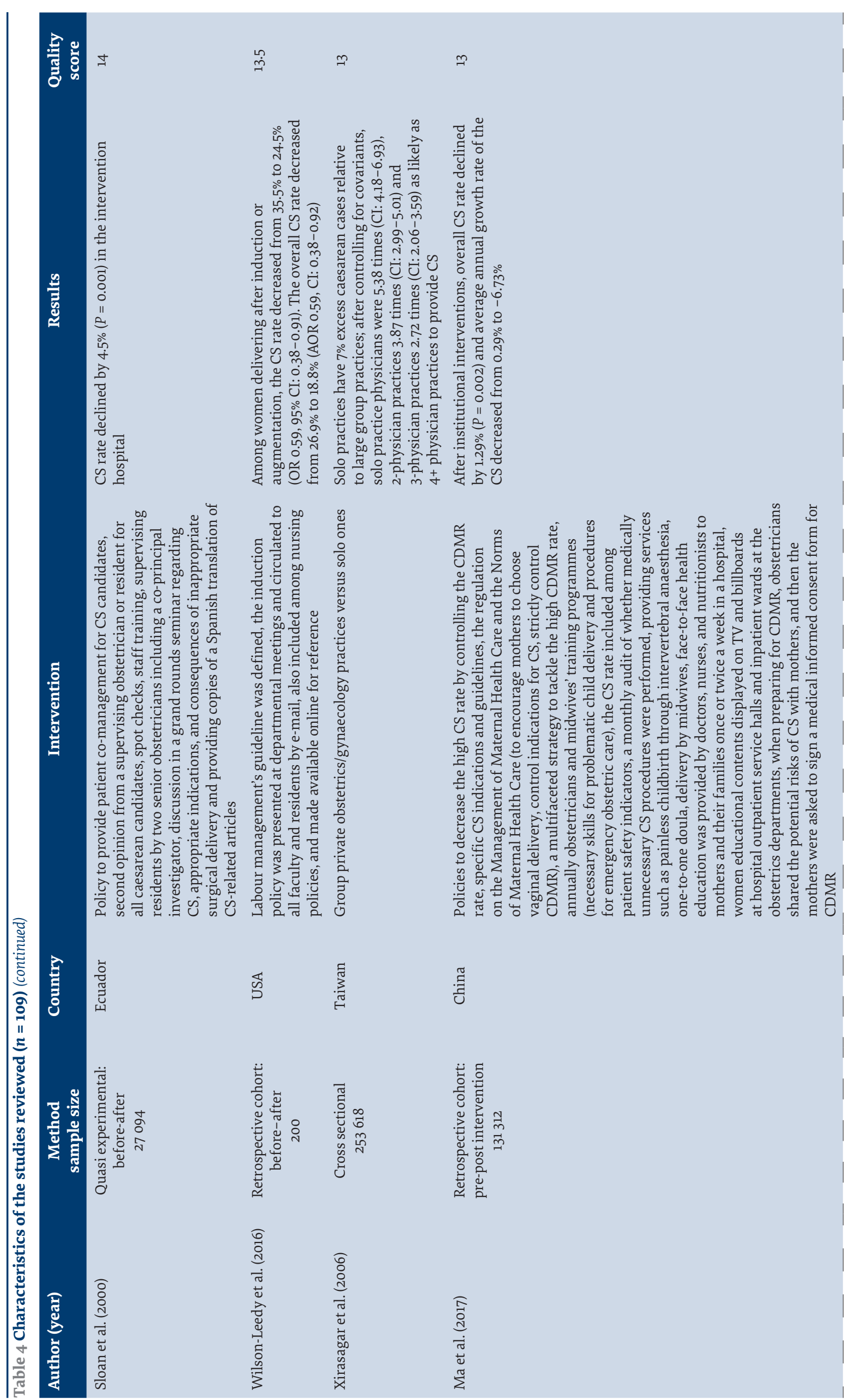




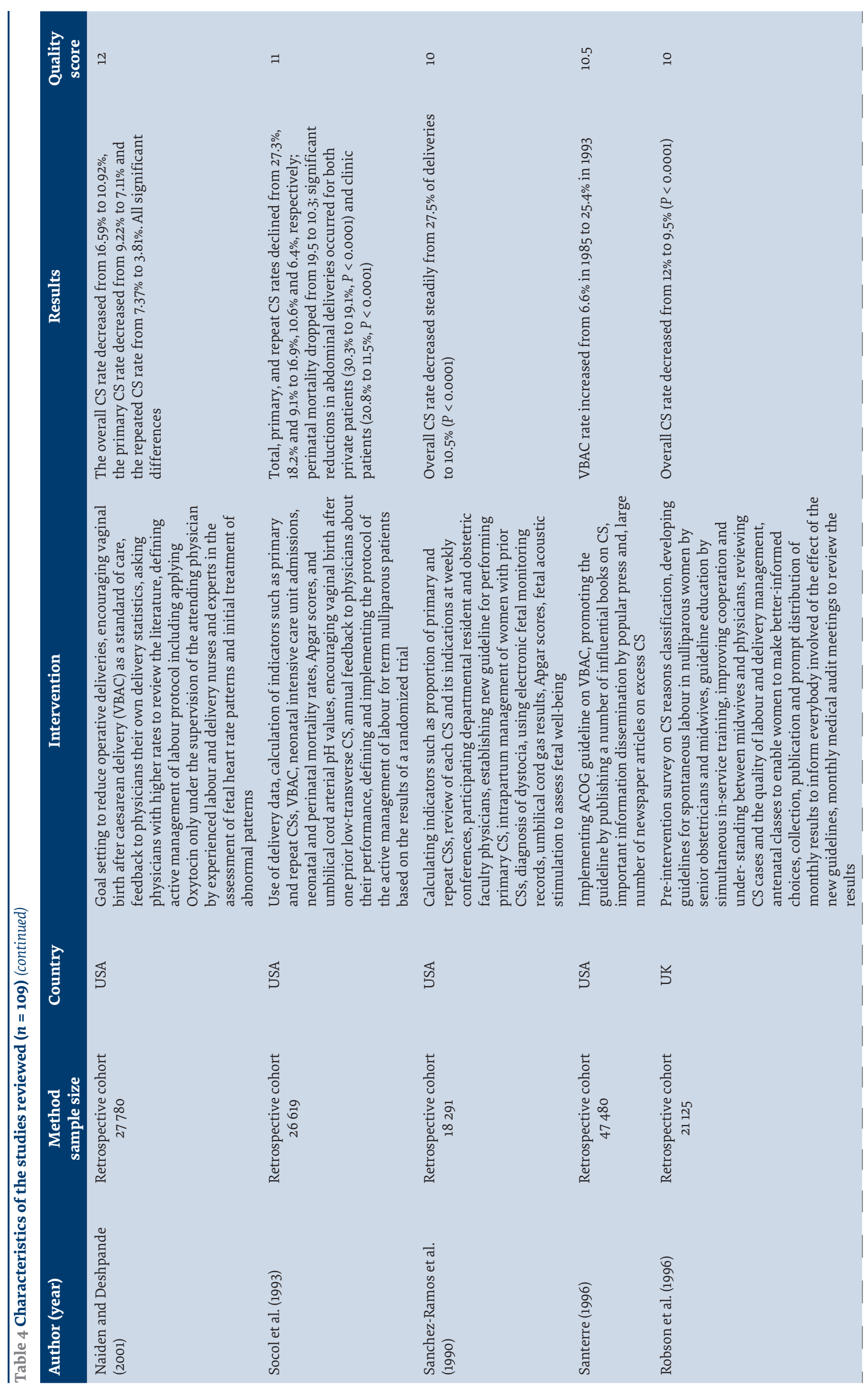




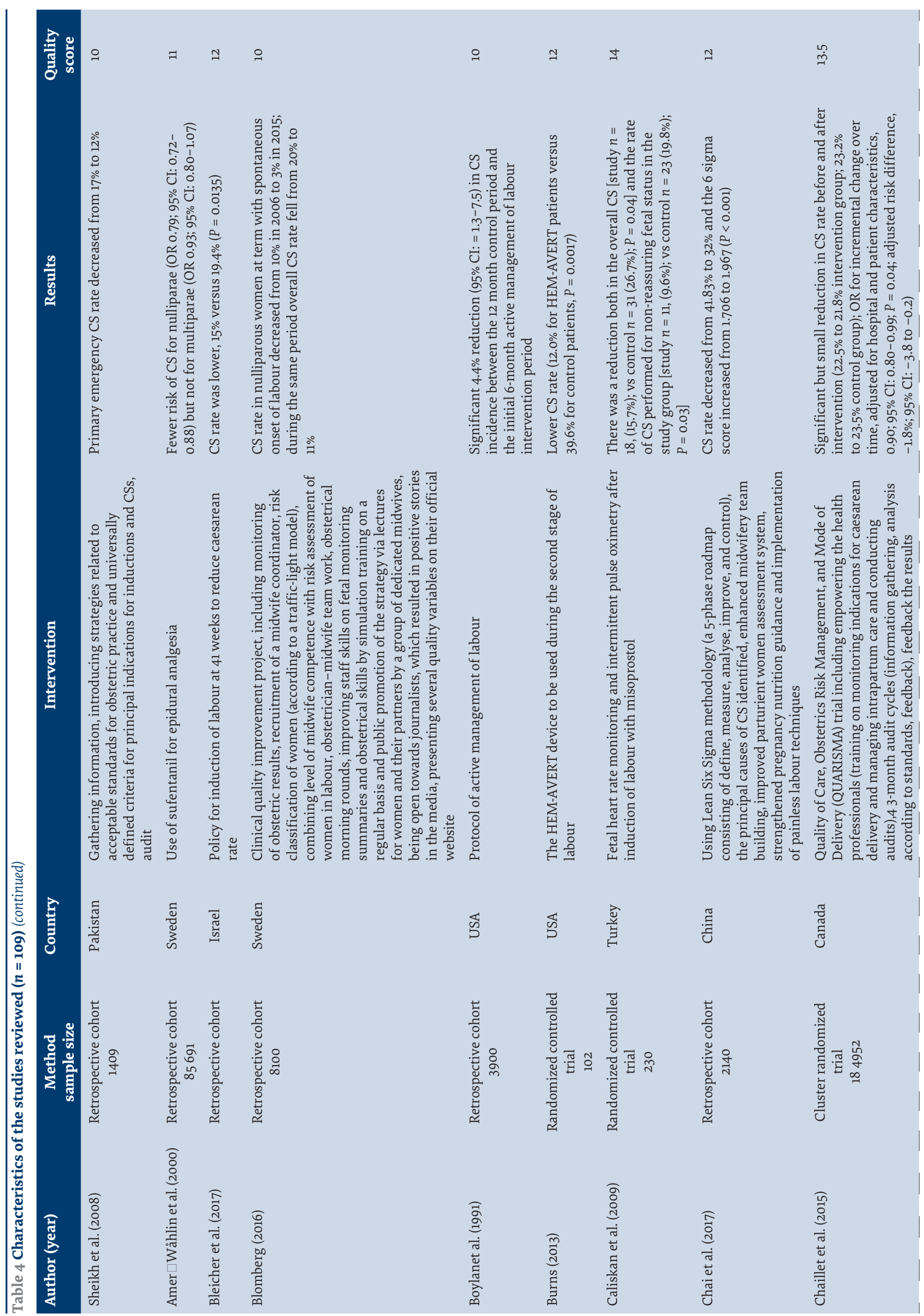




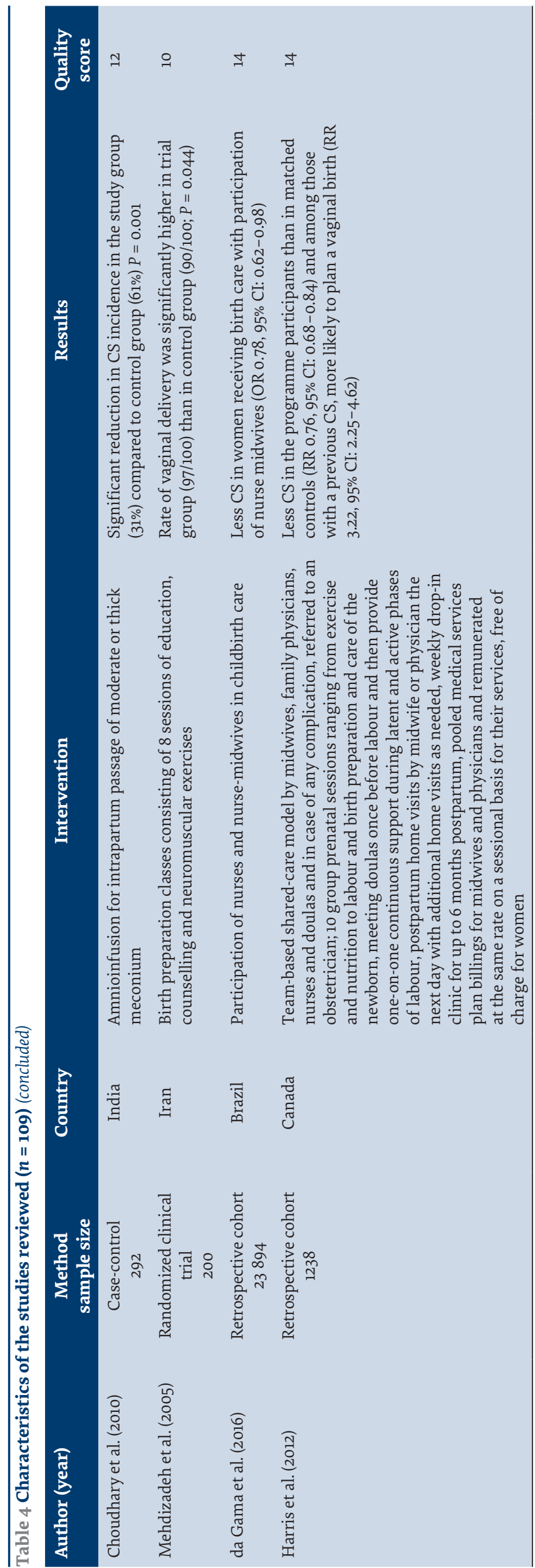

Leadership helped create confidence among the maternity team and encouraged a positive environment for adherence to protocols and cooperation in CS reduction plans. This was achieved by physician leaders and chiefs of obstetrics (31) or leading midwives (25).

\section{Financing}

The financing building block consisted of institution and provider reimbursement interventions. Institutions were paid via different methods, and some, e.g. fee-for-service, may drive CS overuse. Fixed payment and pay-for-performance strategies were associated with a decrease in caesareans. The blended payment method used in the USA (32) and the global budget system in Taiwan (33) are examples of fixed payments. In addition, pay-for-performance in the form of bonuses and financial support of obstetrics centres with appropriate CS rates (30) or a pay cut for non-medically indicated caesareans (34) were conducted.

Individual reimbursement was effective too. This also included fixed payment in form of blended payment (32) and pay-for-performance measures such as larger salary bonus for providers with a favourable CS ranking (30).

\section{Health worlkforce}

Interventions related to recruiting qualified and competent staff and teamwork are subgroups of the health workforce building block. Recruiting qualified and competent staff was the most commonly used intervention in the studies we reviewed. It was attained by optimizing the available workforce through employing freestanding midwives to care for low risk women (35), doulas for continuous support in labour (36), full-time labourists and obstetric patient safety nurses for hospitals (28). Another example, from Linköping hospital, Sweden, was assigning a mix of midwives with different levels of competency, ranging from midwife coordinator (highest level) to new graduate midwives (lowest level), in each working shift in order to combine the level of midwives' competence with the risk assessment of women in labour (37).

Staff education and training are essential to having a competent workforce. Courses such as clinical guidelines education (38), electronic fetal monitoring interpretation (28) and effective teamwork workshops (28) were found to be beneficial. For this purpose various methods of training such as lectures, drills, Internet-based assignment (28) and on-site training were used (27). Considering the role of obstetrics residents in providing quality maternity care, recruiting a senior obstetrician-gynaecologist to train and supervise staff (39) and including residents in staff training programmes (27) were noted. Moreover, as the attitude of staff towards normal delivery is of importance, measures such as periodical meetings to standardize clinical activities (40), asking staff to review literature on CS (41) and characterizing non-medical CS as "unnecessary CS" in hospital records (33) were employed.

Teamwork was the other essential component of this block. Group private practice compared to solo obstetricians was associated with a lower rate of CS (42). 
Collaborative continuous care was another successful action in Australia, where a team of midwives and obstetricians provided antenatal and intra-partum care for women. Shifts were scheduled so one of the familiar providers was always on call to take care of women in hospital (23).

\section{Medical products and technologies}

Medicines, equipment and technology were classified under this building block. Some medicines, like misoprostol, used for labour induction, (43) and sufentanil combined with epidurals to relieve labour pain (44) were associated with a lower caesarean rate.

Some devices and techniques were also applied to facilitate normal birth. Techniques such as external cephalic version for breech pregnancies (45) and manual cephalic rotation in persistent transverse or posterior vertex position (46) increased the chance of normal vaginal delivery. Use of the "Baby-guard system" in Italy (47) and the "peanut ball" in the USA (21) were also reported as effective. Technologies to assess fetal well-being such as amnioinfusion, chemical fetal health assessment, fetal ultrasound, non-stress test, biophysical profile and umbilical wave were also used $(48,49)$

\section{Information}

Health information building blocks comprised interventions such as data-gathering and analysis, and information dissemination. To gather related data, electronic medical records were used (21) and indicators like total caesarean, primary caesarean, vaginal birth after caesarean (VBAC), induction rates and maternal and neonatal outcomes were measured (21,50-52). Caesarean classification groups such as the Robson CS classification, based on presentation of fetus, gestational age, parity, number of fetuses, previous uterine scar and initiation of labour, were used in a hospital in Chile and resulted in a 10\% decrease in CS (52).

In a hospital in Colorado, USA, caesarean-related information was disseminated by providing individual feedback to physicians in hospital section meetings, via e-mail or on a dashboard (26). Additionally, measures such as releasing information via popular press agencies in the USA (53) or publishing it on the hospital's official website in Sweden (37) were found effective.

\section{Service delivery}

Prenatal and intra-partum services were categorized in the service delivery building block. Prenatal services such as dietary counselling, specifically for women with body mass index $>35 \mathrm{~kg} / \mathrm{m}^{2}$ in Australia (54), and the prenatal exercise plan in Spain were associated with lower CS rates (55). Fear control through cognitive therapy and psychoprophylaxis were also effective $(55,56)$.

Pregnant women and their families participated in educational programmes such as birth preparation classes. They learnt about the physical and emotional changes in pregnancy, advantages and disadvantages of different modes of birth (57), nutrition in pregnancy (20), controlling fear of pain (58), relaxation techniques (59) and VBAC (45). Considering the fact that safe VBAC and external cephalic version for breech pregnancies would result in fewer caesareans, special prenatal clinics like the Next Birth After Caesarean (NBAC) clinic in Australia and the Breech Clinic in Ireland were established $(45,60)$.

Intra-partum services, including protocol-based practice, continuous care, physical and emotional support, physiologic birth, pain control and VBAC, were the most commonly used interventions to reduce CSs. Guidelines were developed and used for defining dystocia, fetal distress and indications for induction in Taiwan (49). Using guidelines for performing primary CS, intra-partum management of women with prior CS and a diagnosis of dystocia were beneficial in lowering the CS rate (from $28 \%$ to $11 \%$ ) in a teaching hospital in the USA (61). Continuous care and physical and emotional support during labour, and delivery by a partner (40), midwife (23) or doula (36) were also effective.

The physiologic approach to birth, which defines pregnancy as a normal event in a woman's life with attempt to keep labour and delivery as natural as possible, with the least unnecessary medical interventions, was important (21). In Italy, encouraging the presence of the partner and free access to caloric snacks, foods and water along with other interventions resulted in a significant reduction in CS, from $22.2 \%$ to $10.3 \%$ (40).

Although a variety of pain relief services are available, most studies focused on regional anaesthesia such as epidurals (27,30). Likewise, providing VBACs also lowered the CS rate (31).

\section{Discussion}

This systematic review aimed to identify and classify interventions effective in reducing the number4 of unnecessary CSs using a health system approach. A systemic horizontal approach is indeed critical to addressing complex health problems such as excessive CSs and achieving the best sustained results. The WHO has proposed the 6 building blocks framework as the perquisite to achieving the health systems goals (16). These building blocks interact with each other and also with external environment factors such as political, economic, social, technological and legal factors. The quality of these building blocks and their internal and external interactions affect the achievement of the health systems goals (62). An alphabetically arranged list of the full references for the studies we reviewed is given in Table 5 .

Governance and leadership interventions were applied to reduce caesarean delivery on maternal request in China. This policy required maternity care providers to encourage mothers to choose vaginal birth, and rigorously to control CS indications. The caesarean rate was considered an important indicator, and professionals who did not maintain the CS rate within a reasonable range would face financial penalties. These measures resulted in an $8 \%$ reduction in CS (20). Financing interventions such as "blended payment" was adopted 
for normal deliveries and uncomplicated caesareans in the USA. The payment for uncomplicated childbirth (both CS and normal vaginal delivery) was $\$ 3528$ for facilities and $\$ 867.37$ for individuals. Facility fees used to be $\$ 3144$ for normal vaginal delivery and $\$ 5266$ for CS, and professional fees for prenatal, delivery and postpartum care were $\$ 776.62$ for normal vaginal delivery and $\$ 1147.42$ for CS. Reducing financial incentives was effective in lowering unnecessary caesareans 0.27 percentage points per quarter after the intervention. Comparing with control states, the CS rate decreased $3.24 \%$ overall (32).

Recruiting the right health workforce proved to be effective too. Providing comprehensive and collaborative care by family physicians, community health nurses, midwives and doulas and referring pregnant women to an obstetrician if medically needed resulted in fewer caesareans $(21.1 \%)$ compared with standard care $(31.3 \%)$ in Canada (63). Additionally, applying medical technology such as electronic fetal monitoring, scalp pH sampling and fetal acoustic stimulation helped clinicians assess and manage dystocia and fetal distress, and reduced the overall CS from $27.5 \%$ to $10.5 \%$ in the USA (61).

The health information system enabled policymakers to design and implement effective evidencebased interventions. The Robson CS classification system was used for assessing and monitoring caesareans in Chile. Each group caesarean rate, the relative size of groups and contribution of each group to the overall CS rate were assessed. Auditing caesareans based on this classification system reduced the numbers in groups 1 , 5a and 10 significantly. Overall, the CS rate also dropped from $36.8 \%$ to $31.8 \%$ after this intervention (52). Providing the right health services such as protocol-based intrapartum services and supporting normal physiological birth and prenatal services like women's education and VBAC counselling lowered the CS rate by $4 \%$ in a hospital in Canada (31).

The most successful plans were those comprehensive plans which were organized in a systematic way. For example, the "Patient Safety Bundle" in North Carolina successfully reduced the CS rate in nulliparous women. It embraced several actions such as goal-setting, protocolbased labour management, staff education, mothers' education, facilitating physiologic birth, providing labour support and pain relief, gathering and analysing data, CS audit and feedback to the physicians (21).
The International Federation of Gynecology and Obstetrics (FIGO) also suggested governments, professional organizations, women's groups, and other stakeholders could help reduce unnecessary CSs through actions such as using the Robson CS classification, informing women, better care, pain relief, practical skills training for doctors and midwives, the reintroduction of vaginal instrumental deliveries, publishing annual hospital CS rates and financing partly based on CS rates (64). This would be more comprehensive by adding certain interventions such as optimizing the workforce, improving the attitudes of health care providers towards the culture of normality of pregnancy and birth, designing mother-centred models of care and developing proper financing.

Considering the fact that recent WHO statements and publications on CS have attracted global attention to the problem of overuse, it seems that governance and leadership interventions such as legislation, policymaking, planning, promotion, oversight and leadership by international organizations like WHO would strengthen national CS control plans. Periodic publications about CS, holding frequent regional and international conferences on this issue and naming one day of the year as "Birth is Normal" might be helpful promotional plans to cut unnecessary CSs. Considering the CS rate as a component of the Maternal Health Index combined with other main maternal health indicators to be monitored by WHO has also been suggested.

Last but not least, comprehensive CS reduction strategies at the hospital level covering governance, financing, human resources, equipment, information and service delivery processes should be supported by strengthening its subsystems, i.e. the involvement and commitments of professionals and mothers and the super systems, the health policy-makers.

This systematic review using an exploratory approach identified 16 effective interventions and 45 actions for reducing unnecessary CS by examining the findings of 109 related studies. More research should be conducted, particularly in the Africa, South-East Asia and Eastern Mediterranean regions of WHO to augment the findings of this study. Furthermore, it would be of interest to compare the efficacy of these interventions to see which are more effective at reducing unnecessary CS.

Funding: None.

Competing interests: None declared.

\section{Taxonomie des stratégies efficaces pour réduire les césariennes inutiles : une analyse systématique \\ Résumé}

Contexte : La tendance croissante au recours à des césariennes inutiles a suscité des inquiétudes pour la santé maternelle et néonatale dans le monde entier. Diverses interventions médicales et non médicales ont été élaborées et mises en œuvre pour réduire le recours excessif aux césariennes. Cependant, leur efficacité reste contestable.

Objectifs : La présente étude visait à identifier et à classer les interventions efficaces pour réduire le nombre des césariennes inutiles. 
Méthodes : Nous avons recherché des articles dans les bases de données EMBASE, MEDLINE, Web of Knowledge et Scopus, en utilisant des stratégies de recherche appropriées, jusqu'au 2 juin 2020. Au total, 7951 articles identifiés ont été analysés et évalués en utilisant une liste de contrôle valide pour l'évaluation de la qualité. Finalement, 109 études éligibles ont été incluses dans cette analyse. Une analyse de contenu thématique a été utilisée pour identifier et classer les interventions efficaces.

Résultats: Au total, 188 mesures efficaces visant à réduire le nombre de césariennes ont été identifiées. Elles ont été réparties en 45 mesures à prendre, 16 groupes d'intervention et 6 blocs constitutifs de l'OMS, notamment « gouvernance et leadership », «financement », «personnels de santé », «produits et technologies médicales », « information » et «prestation de services ». Parmi les interventions les plus couramment appliquées pour réduire le nombre de césariennes inutiles, on peut citer le recours à un personnel qualifié et compétent, aux services offerts pendant l'accouchement et à la surveillance.

Conclusions: Une taxonomie des stratégies efficaces pour réduire le nombre des césariennes inutiles a été mise au point dans cette étude. Une approche holistique est essentielle pour lutter contre la nouvelle vague de césariennes inutiles. Des interventions multiples basées sur les causes fondamentales du recours excessif aux césariennes devraient être élaborées et mises en œuvre aux niveaux local et mondial.

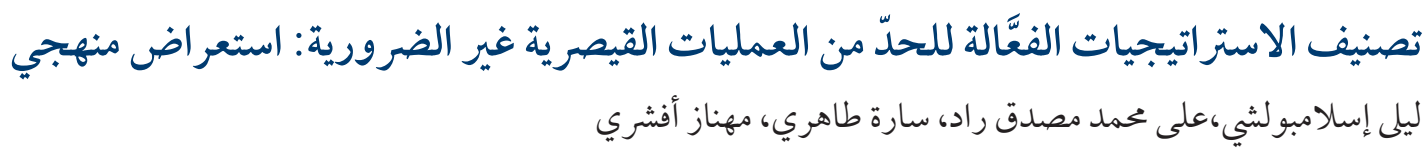

الخلفية: تسبَّب الاتجاه المتز ايد لإجر اء العمليات القيصرية غير الضرورية في ظهور خخاوف على صحة الأمهات وحديثي الولادة في جميع أنحاء العالم.

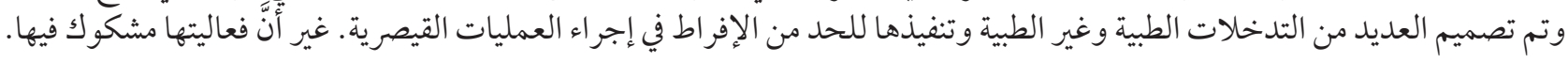
الأهداف: هدفت هذه الدر اسة إلى تحديد التدخلات الفعَّالة وتصنيفها للحدِّ من العمليات القيصرية غير الضرورية.

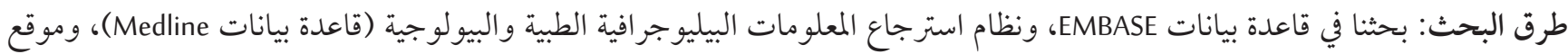

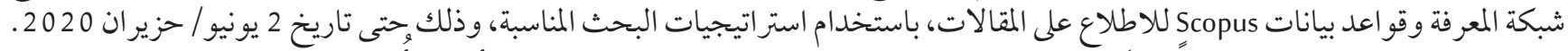

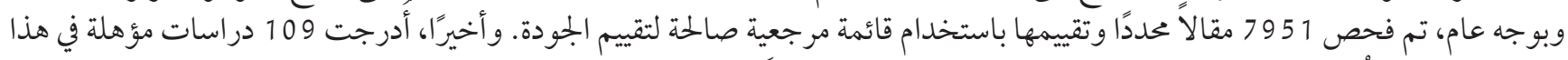

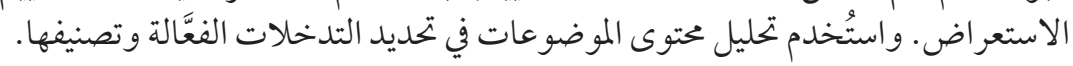

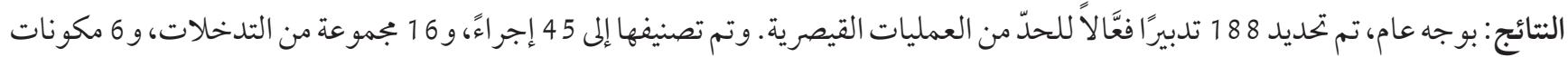

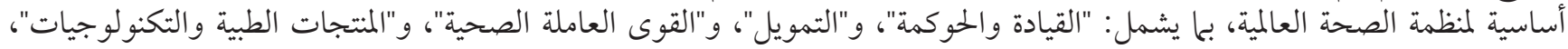

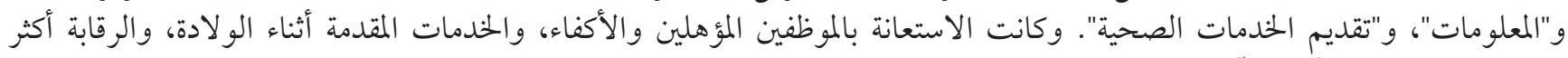

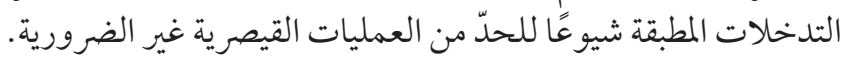

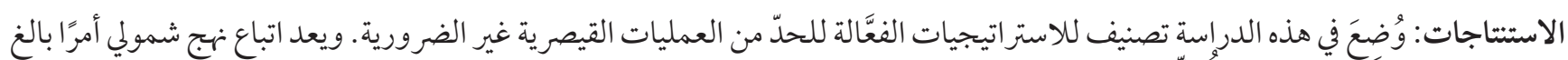

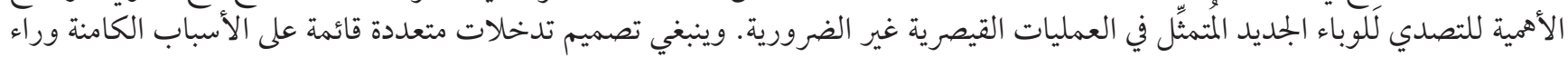

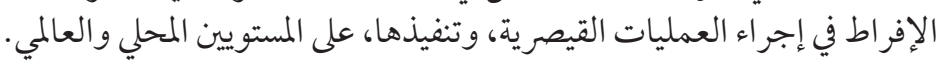

\section{References}

1. Bailey P, Lobis S, Maine D, Fortney JA. Monitoring emergency obstetric care: a handbook. Geneva: World Health Organization; 2009.

2. No authors listed. Appropriate technology for birth. Lancet 1985;2(8452):436-467. PMID:2863457

3. WHO statement on caesarean section rates. Geneva: World Health Organization; 2015.

4. Betrán AP, Ye J, Moller A-B, Zhang J, Gülmezoglu AM, Torloni MR. The increasing trend in caesarean section rates: global, regional and national estimates: 1990-2014. PLoS One. 2016;11(2):e0148343. doi:10.1371/journal.pone.0148343

5. Gibbons L, Belizán JM, Lauer JA, Betrán AP, Merialdi M, Althabe F, et al. The global numbers and costs of additionally needed and unnecessary caesarean sections performed per year: overuse as a barrier to universal coverage. In: World Health Report (2010) - health systems financing: the path to universal coverage. Background Paper, No. 30. Geneva: World Health Organization; 2010:30(1):1-31.

6. WHO recommendations non-clinical interventions to reduce unnecessary caesarean sections. Geneva: World Health Organization; 2018. 
7. Fenwick J, Staff L, Gamble J, Creedy DK, Bayes S. Why do women request caesarean section in a normal, healthy first pregnancy? Midwifery.2010;26(4):394-400. doi:10.1016/j.midw.2008.10.011

8. Gamble JA, Creedy DK. Women's preference for a cesarean section: incidence and associated factors. Birth.2001;28(2):101-10. doi:10.1046/j.1523-536x.2001.00101.x

9. Betrán AP, Temmerman M, Kingdon C, Mohiddin A, Opiyo N, Torloni MR, et al. Interventions to reduce unnecessary caesarean sections in healthy women and babies. Lancet. 2018;392(10155):1358-68. doi:10.1016/So140-6736(18)31927-5

10. Sandall J, Tribe RM, Avery L, Mola G, Visser GH, Homer CS, et al. Short-term and long-term effects of caesarean section on the health of women and children. Lancet. doi:10.1016/So140-6736(18)31930-5 2018;392(10155):1349-57.

11. Madeley J. Sustainable development goals. Appropriate Technol. 2015 Dec 1;42(4):32.

12. Hodnett ED, Gates S, Hofmeyr GJ, Sakala C. Continuous support for women during childbirth. Cochrane database of systematic reviews. 2013;7:CD003766. doi:10.1002/14651858.CD003766.pub5.

13. Weaver J, Browne J, Aras-Payne A, Magill-Cuerden J. A comprehensive systematic review of the impact of planned interventions offered to pregnant women who have requested a caesarean section as a result of tokophobia (fear of childbirth). JBI Libr Syst Rev. 2012;10(28 Suppl.):1-20. doi:10.11124/jbisrir-2012-322

14. Smith V, Gallagher L, Carroll M, Hannon K, Begley C. Antenatal and intrapartum interventions for reducing caesarean section, promoting vaginal birth, and reducing fear of childbirth: an overview of systematic reviews. PloS One. 2019 Oct 24;14(10):e0224313. doi:10.1371/journal.pone.0224313

15. Chen I, Opiyo N, Tavender E, Mortazhejri S, Rader T, Petkovic J, et al. Non $\nabla$ clinical interventions for reducing unnecessary caesarean section. Cochrane Database Syst Rev. 2018 Sep 28;9(9):CDo05528. doi:10.1002/14651858.CDo05528.pub3

16. Everybody's business: strengthening health systems to improve health outcomes: WHO's framework for action. Geneva: World Health Organization; 2007.

17. Moher D, Liberati A, Tetzlaff J, Altman DG. Preferred reporting items for systematic reviews and meta-analyses: the PRISMA statement. Int J Surg. 2010 Jan 1;8(5):336-41. doi:10.1016/j.ijsu.2010.02.007

18. Mitton C, Adair CE, Perry BW. Knowledge transfer and exchange: review and synthesis of the literature. Milbank Q. 2007;85:729-68. doi:10.1111/j.1468-0009.2007.00506.x

19. Dahlen HM, McCullough JM, Fertig AR, Dowd BE, Riley WJ. Texas Medicaid payment reform: fewer early elective deliveries and increased gestational age and birthweight. Health Aff. 2017;36(3):460-7. doi:10.1377/hlthaff.2016.0910

20. Yu Y, Zhang X, Sun C, Zhou H, Zhang Q, Chen C. Reducing the rate of cesarean delivery on maternal request through institutional and policy interventions in Wenzhou, China. PloS One. 2017;12(11):e0186304. doi:10.1371/journal.pone.0186304

21. Bell AD, Joy S, Gullo S, Higgins R, Stevenson E. Implementing a systematic approach to reduce cesarean birth rates in nulliparous women. Obstet Gynecol. 2017 Nov;130(5):1082-1089. doi:10.1097/AOG.0000000000002263

22. Safari-Faramani R, Haghdoost AA, Nakhaei N, Foroudnia S, Mahmoodabadi Z, Safizadeh M. First birth cesarean proportion: a missed indicator in controlling policies. Med J Islam Repub Iran. 2016 Jul 10;30:394. PMID:27579285

23. Homer CS, Davis GK, Brodie PM, Sheehan A, Barclay LM, Wills J, Chapman MG. Collaboration in maternity care: a randomised controlled trial comparing communityవbased continuity of care with standard hospital care. BJOG. 2001 Jan;108(1):16-22. doi:10.1111/j.1471-0528.2001.00022.x

24. Davies-Tuck ML, Wallace EM, Davey MA, Veitch V, Oats J. Planned private homebirth in Victoria 2000-2015: a retrospective cohort study of Victorian perinatal data. BMC Pregnancy Childbirth. 2018 Dec 1;18(1):357. doi:10.1186/s12884-018-1996-6

25. Chai ZY, Hu HM, Ren XL, Zeng BJ, Zheng LZ, Qi F. Applying Lean Six Sigma methodology to reduce cesarean section rate. J Eval Clin Pract. 2017 Jun;23(3):562-6. doi:10.1111/jep.12671

26. Javernick JA, Dempsey A. Reducing the primary cesarean birth rate: a quality improvement project. J Midwifery Womens Health. 2017 Jul;62(4):477-83. doi:10.1111/jmwh.12606

27. Hu LQ, Flood P, Li Y, Tao W, Zhao P, Xia Y, et al. No pain labor \& delivery: a global health initiative's impact on clinical outcomes in China. Anesth Analg. 2016 Jun;122(6):1931-8. doi:10.1213/ANE.0000000000001328

28. Grunebaum A, Dudenhausen J, Chervenak FA, Skupski D. Reduction of cesarean delivery rates after implementation of a comprehensive patient safety program. J Perinat Med. 2013 Jan;41(1):51-5. doi:10.1515/jpm-2012-0181

29. Hoskins IA, Ellison T, Ruggiero R. A multi-strategy approach for Cesarean section reduction at an urban community medical center. J Reproductive Med. 2017 Sep 1;62(9-10):469-74.

30. Liu X, Lynch CD, Cheng WW, Landon MB. Lowering the high rate of caesarean delivery in China: an experience from Shanghai. BJOG. 2016;123(10):1620-8. doi:10.1111/1471-0528.14057

31. Shoemaker ES, Bourgeault IL, Cameron C, Graham ID, Hutton EK. Results of implementation of a hospital $\triangle$ based strategy to reduce cesarean delivery among lowవrisk women in Canada. Int J Gynaecol Obstet. 2017 Nov;139(2):239-44. doi:10.1002/ijgo.12263

32. Kozhimannil KB, Graves AJ, Ecklund AM, Shah N, Aggarwal R, Snowden JM. Cesarean delivery rates and costs of childbirth in a state Medicaid program after implementation of a blended payment policy. Med Care. 2018 Aug 1;56(8):658-64. doi:10.1097/ MLR.0000000000000937 
33. Liu CM, Lin YJ, Su YY, Chang SD, Cheng PJ. Impact of health policy based on the self-management program on cesarean section rate at a tertiary hospital in Taiwan. J Formos Med Assoc. 2013 Feb;112(2):93-8. doi:10.1016/j.jfma.2011.12.005

34. Runmei M, Terence T, Yonghu S, Hong X, Yuqin T, Bailuan L, et al. Practice audits to reduce caesareans in a tertiary referral hospital in south-western China. Bull World Health Organ. 2012 Jul 1;90(7):488-94. doi:10.2471/BLT.11.093369

35. Grigg CP, Tracy SK, Tracy M, Daellenbach R, Kensington M, Monk A, et al. Evaluating maternity units: a prospective cohort study of freestanding midwife-led primary maternity units in New Zealand-clinical outcomes. BMJ Open. 2017 Aug 1;7(8):e016288. doi:10.1136/bmjopen-2017-016288

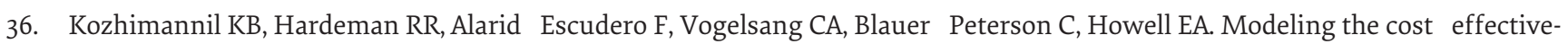
ness of doula care associated with reductions in preterm birth and cesarean delivery. Birth. 2016;43(1):20-7. doi:10.1111/birt.12218

37. Blomberg M. Avoiding the first cesarean section: results of structured organizational and cultural changes. Acta Obstet Gynecol Scand. 2016 May;95(5):580-6. doi:10.1111/aogs.12872

38. Berglund A, Lefevre-Cholay H, Bacci A, Blyumina A, Lindmark G. Successful implementation of evidence-based routines in Ukrainian maternities. Acta Obstet Gynecol Scand. 2010;89(2):230-7. doi:10.3109/00016340903479894

39. Bardos J, Loudon H, Rekawek P, Friedman F, Brodman M, Fox NS. Association between senior obstetrician supervision of resident deliveries and mode of delivery. Obstet Gynecol. 2017 Mar;129(3):486-90. doi:10.1097/AOG.0000000000001910

40. Ragusa A, Gizzo S, Noventa M, Ferrazzi E, Deiana S, Svelato A. Prevention of primary caesarean delivery: comprehensive management of dystocia in nulliparous patients at term. Arch Gynecol Obstet. 2016;294(4):753-61. doi:10.1007/s00404-016-4046-5

41. Naiden J, Deshpande P. Using active management of labor and vaginal birth after previous cesarean delivery to lower cesarean delivery rates: a 10-year experience. Am J Obstet Gynecol. 2001 Jun;184(7):1535-41; discussion 1541-3. doi:10.1067/mob.2001.114865

42. Xirasagar S, Lin HC, Liu TC. Do group practices have lower caesarean rates than solo practice obstetric clinics? Evidence from Taiwan. Health Policy Plan. 2006;21(4):319-25. doi:10.1093/heapol/czlo15

43. Beigi A, Kabiri M, Zarrinkoub F. Cervical ripening with oral misoprostol at term. Int J Gynecol Obstet. 2003;83(3):251-5. doi:10.1016/s0020-7292(03)00275-3

44. Amer-Wåhlin I, Christoffersson M, Dahlgren N, Rydhstroem H. Epidural analgesia with sufentanil during labor and operative delivery. Acta Obstet Gynecol Scand. 2000 Jul;79(7):538-42. PMID: 10929951

45. Hickland P, Gargan P, Simpson J, McCabe N, Costa J. A novel and dedicated multidisciplinary service to manage breech presentation at term; 3 years of experience in a tertiary care maternity unit. J Matern Fetal Neonatal Med. 2018 Nov;31(22):3002-8. do i:10.1080/14767058.2017.1362382

46. Shaffer BL, Cheng YW, Vargas JE, Caughey AB. Manual rotation to reduce caesarean delivery in persistent occiput posterior or transverse position. J Matern Fetal Neonatal Med. 2011 Jan;24(1):65-72. doi:10.3109/14767051003710276

47. Acanfora L, Rampon M, Filippeschi M, Marchi M, Montisci M, Viel G, Cosmi E. An inflatable ergonomic 3মchamber fundal pressure belt to assist vaginal delivery. Int J Gynaecol Obstet. 2013 Jan;120(1):78-81. doi:10.1016/j.ijgo.2012.07.025

48. Choudhary D, Bano I, Ali SM. Does amnioin fusion reduce caesarean section rate in meconium-stained amniotic fluid. Arch Gynecol Obstet. 2010 Jul;282(1):17-22. doi:10.1007/s00404-009-1196-8

49. Peng FS, Lin HM, Lin HH, Tu FC, Hsiao CF, Hsiao SM. Impact of clinical audits on cesarean section rate. Taiwan J Obstet Gynecol. 2016 Aug;55(4):530-3. doi:10.1016/j.tjog.2014.12.015

50. Gregory KD, Hackmeyer P, Gold L, Johnson AI, Platt LD. Using the continuous quality improvement process to safely lower the cesarean section rate. Jt Comm J Qual Improv. 1999 Dec;25(12):619-29. doi:10.1016/s1070-3241(16)30476-X

51. Mohammadi S, Källestål C, Essen B. Clinical Audits: a practical strategy for reducing cesarean section rates in a general hospital in Tehran, Iran. J Reprod Med. 2012;57(1-2):43-8. PMID: 22324267

52. Scarella A, Chamy V, Sepúlveda M, Belizán JM. Medical audit using the Ten Group Classification System and its impact on the cesarean section rate. Eur J Obstet Gynecol Reprod Biol. 2011 Feb;154(2):136-40. doi:10.1016/j.ejogrb.2010.09.005

53. Santerre RE. The effect of the ACOG guideline on vaginal births after cesarean. Med Care Res Rev. 1996 Sep;53(3):315-29. doi:10.1177/107755879605300306

54. Robertson N, Ladlow B. Effect of individual dietetic intervention on gestational weight gain and associated complications in obese pregnant women. Aust N Z J Obstet Gynaecol. 2018 Jun;58(3):274-7. doi:10.1111/ajo.12711

55. Barakat R, Pelaez M, Lopez C, Montejo R, Coteron J. Exercise during pregnancy reduces the rate of cesarean and instrumental deliveries: results of a randomized controlled trial. J Matern Fetal Neonatal Med. 2012 Nov;25(11):2372-6. doi: 10.3109/14767058.2012.696165

56. Bergström M, Kieler H, Waldenström U. Psychoprophylaxis during labor: associations with labor-related outcomes and experience of childbirth. Acta Obstet Gynecol Scand. 2010 Jun;89(6):794-800. doi:10.3109/00016341003694978

57. Poma PA. Effect of departmental policies on cesarean delivery rates: a community hospital experience. Obstet Gynecol. 1998 Jun 1;91(6):1013-8. doi:10.1016/s0029-7844(98)00077-5

58. Navaee M, Abedian Z. Effect of role play education on primiparous women's fear of natural delivery and their decision on the mode of delivery. Iran J Nurs Midwifery Res. 2015 Jan-Feb;20(1):40-6. PMID: 25709689 
59. Bastani F, Hidarnia A, Montgomery KS, Aguilar-Vafaei ME, Kazemnejad A. Does relaxation education in anxious primigravid Iranian women influence adverse pregnancy outcomes?: a randomized controlled trial. Perinat Neonatal Nurs. 2006 AprJun;20(2):138-46. doi:10.1097/00005237-200604000-0000

6o. Gardner K, Henry A, Thou S, Davis G, Miller T. Improving VBAC rates: the combined impact of two management strategies. Aust N Z J Obstet Gynaecol. 2014 Aug;54(4):327-32. doi:10.1111/ajo.12229

61. Sanchez-Ramos L, Kaunitz AM, Peterson HB, Martinez-Schnell B, Thompson RJ. Reducing cesarean sections at a teaching hospital. Am J Obstet Gynecol. 1990;163(3):1081-8. doi:10.1016/0002-9378(90)91132-v

62. Mosadeghrad AM. [Health strengthening plan, a supplement to Iran health transformation plan: letter to the editor]. Tehran Univ Med J. 2019;77 (8):537-8 (in Farsi)

63. Harris SJ, Janssen PA, Saxell L, Carty EA, MacRae GS, Petersen KL. Effect of a collaborative interdisciplinary maternity care program on perinatal outcomes. CMAJ. 2012 Nov 20;184(17):1885-92. doi:10.1503/cmaj.111753

64. Visser GH, Ayres-de-Campos D, Barnea ER, de Bernis L, Di Renzo GC, Vidarte MF, et al. FIGO position paper: how to stop the caesarean section epidemic. Lancet. 2018 Oct 13;392(10155):1286-7. doi:10.1016/So140-6736(18)32113-5 